Article

\title{
Simultaneous Determination of Chrysin and Tectochrysin from Alpinia oxyphylla Fruits by UPLC-MS/MS and Its Application to a Comparative Pharmacokinetic Study in Normal and Dementia Rats
}

\author{
Xu Zhao ${ }^{1}$, Xin $\mathrm{Su}^{2}$, Chunmei Liu ${ }^{2}$ and Ying Jia ${ }^{1, *}$ \\ 1 Faculty of Functional Food and Wine, Shenyang Pharmaceutical University, Wenhua Road 103, \\ Shenyang 110016, China; zhaoxu_1010@163.com \\ 2 Faculty of Traditional Chinese Materia Medica, Shenyang Pharmaceutical University, Wenhua Road 103, \\ Shenyang 110016, China; 15642828518@163.com (X.S.); liuchunmeicjt@163.com (C.L.) \\ * Correspondence: jiaying@syphu.edu.cn; Tel.:+86-24-2398-6933
}

Received: 23 June 2018; Accepted: 10 July 2018; Published: 12 July 2018

\begin{abstract}
A simple and rapid ultra-performance liquid chromatography-tandem mass spectrometry (UPLC-MS/MS) coupled with a one-step liquid-liquid extraction method has been developed and validated for the simultaneous determination of two flavonoids (chrysin, tectochrysin) from Alpinia oxyphylla fruits extract in rat plasma. Plasma samples were extracted with diethyl ether and separated on an ACQUITY UPLC BEH $C_{18}$ column $(100 \mathrm{~mm} \times 2.1 \mathrm{~mm}, 1.7 \mu \mathrm{m})$ using gradient elution consisting of $0.1 \%$ formic acid in water (A) and methanol (B). The multiple reaction monitoring (MRM) mode with electrospray ionization in the positive ion mode was used for detection. The linear range was $0.1 \mathrm{ng} / \mathrm{mL}$ to $50 \mathrm{ng} / \mathrm{mL}$ for chrysin and tectochrysin, respectively. The accuracy (relative error, $\mathrm{RE} \%$ ) ranged from $-8.8 \%$ to $7.5 \%$ and the intra-day and inter-day precision were within $15 \%$ and had a mean extraction recovery rate of $80.3 \%$ to $86.7 \%$. The validated method was applied to a comparative pharmacokinetic study after oral administration of Alpinia oxyphylla fruit ethanol extract between normal rats and dementia rats. The area under the curve (AUC) and peak plasma concentration $\left(C_{\max }\right)$ of the two constituents were remarkably increased in dementia rats than in normal rats.
\end{abstract}

Keywords: Alpinia oxyphylla; flavonoid; pharmacokinetics; dementia

\section{Introduction}

Alpinia oxyphylla Miq. (Yizhi in Chinese), which is a well-known health food and traditional Chinese medicine (TCM), is widely distributed in Southern China. It is traditionally applied to treat intestinal and urethral disorders [1]. Modern pharmacological studies have indicated that the fruits of Alpinia oxyphylla possess significant pharmacological roles and the underlying mechanisms have been explored by our lab [2-5] as well as other teams [6-10]. Alzheimer's disease (AD) is an age-related neurodegenerative disorder, which disrupts various functions of the brain like intelligence, memory, and learning ability. Amyloid-beta $(A \beta)$ is one of the underlying mechanisms of $\mathrm{AD}$ [11]. Both overproduction or lack of clearance of $\mathrm{A} \beta$ are involved in the neurodegeneration associated with $\mathrm{AD}[12,13]$. Several studies showed that intra-cerebroventricular (i.c.v.) injection of the $\mathrm{A} \beta_{1-42}$ peptides could imitate some signs of $\mathrm{AD}$ including memory impairment, oxidative stress, and neuro-inflammation, which is an accepted dementia modeling method $[2-4,14]$. In the previous studies, we have demonstrated the neuroprotective activity effects of chloroform and n-butanol extracts from the fruits of $A$. oxyphylla in an $\mathrm{A} \beta_{1-42}$-induced AD mouse model. A. oxyphylla improved 
learning and memory deficits by modulating the activation of microglia and the degeneration of neuronal acidophilia, which attenuates oxidative stress and reinforces cholinergic functions $[2,3]$. The total flavonoids of $A$. oxyphylla exerted antidepressant effects by targeting TrkB receptor-mediated $\mathrm{pERK/pCREB/BDNF}$ signal systems [5].

Flavonoids are the main active constituents of $A$. oxyphylla fruits, which have been found to exert various pharmacological activities $[15,16]$. Total and monomeric flavonoid compounds have been found to possess neuroprotective, antioxidant, anti-inflammatory, and anti-apoptosis properties $[5,17,18]$. These active constituents make a great contribution to the neuroprotective effects for A. oxyphylla in vivo. Therefore, it is crucial to decipher their pharmacokinetic (PK) profiles to better elucidate the preclinical characteristics as well as the underlying mechanisms for treatment of a neurodegenerative disorder.

Flavonoids in A. oxyphylla showed low levels in plasma because they mainly formed mono-glucuronide metabolites [19] so it is difficult to determine free flavonoids in plasma. As a result, there are only few analytical methods reporting on the active constituents from A. oxyphylla in bio-samples $[19,20]$. No paper has reported on PK or other preclinical study in dementia model rats. In the present study, by improving previous extraction methods, a simple and rapid UPLC-MS/MS coupled with a one-step liquid-liquid extraction method for simultaneous quantitation of chrysin and tectochrysin in rat plasma has been established and validated. The pharmacokinetic profiles after oral administration of ethanol extract of $A$. oxyphylla fruits were investigated. We have offered a promising approach for the in vivo analysis of active constituents and a foundation for the preclinical study of Alpinia oxyphylla.

\section{Results and Discussion}

\subsection{The Morris Water Maze Test}

The Morris water maze test is a classic method for evaluating memory and spatial learning ability. The performance of the tested objects were evaluated by parameters including the escape latency time to find a platform and swimming time in the target quadrant. As a result, rats in the model group showed a significant delay on the escape latency time compared with the control group on the fifth day of the training $(p<0.01$, Figure 1$)$. The search strategies of the rats on Day 1 and Day 5 were shown in Figure 2. Moreover, on the probe testing day (Day 6), rats treated with $A \beta_{1-42}$ spent less swimming time searching for the platform in the target quadrant after the platform was removed $(p<0.01$, Figure 3$)$. The results indicated that rats treated by A $\beta_{1-42}$ had spatial learning and memory damage in the brain, which led to dementia.

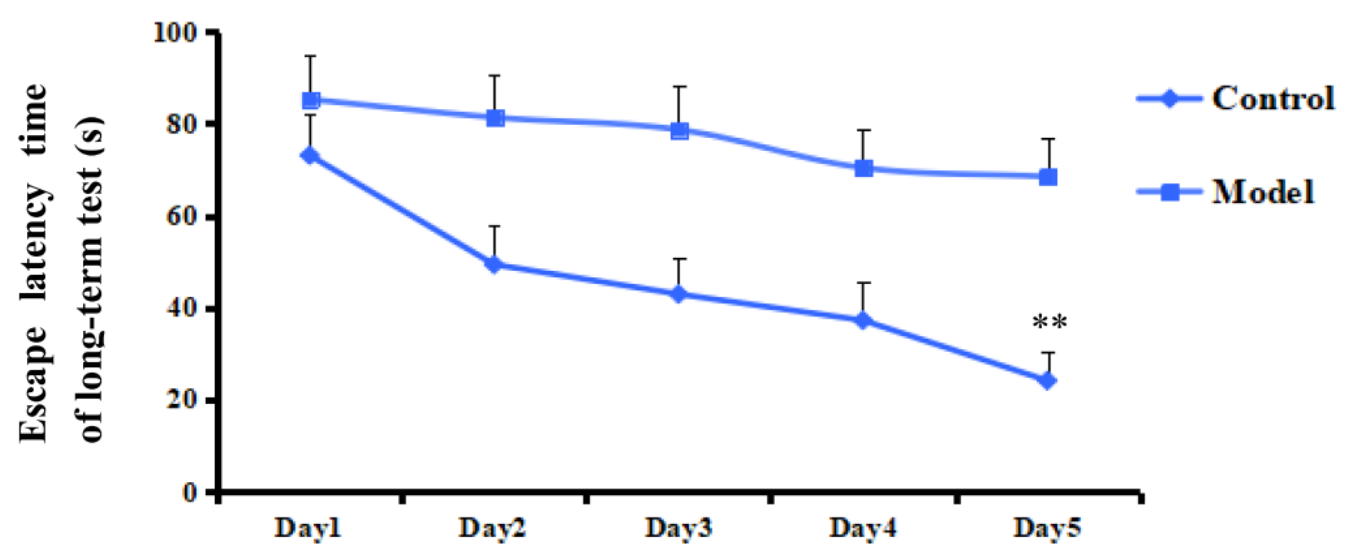

Figure 1. The escape latency time of a long-term test on five days in the Morris water maze test. Data represent means \pm S.E.M. $\left(n=6,{ }^{* *} p<0.01\right.$ compared with the Control group). 


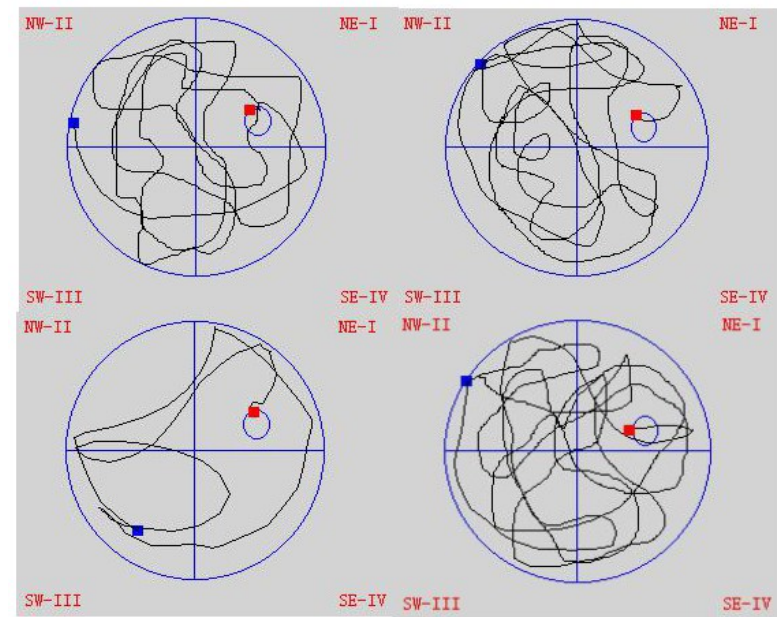

Day 1

Control

Model

Figure 2. The search strategy of the rats on the first and fifth day in the Morris water maze test $(n=6$, blue spot: the initial location of the rats, red spot: the final location of the rats).

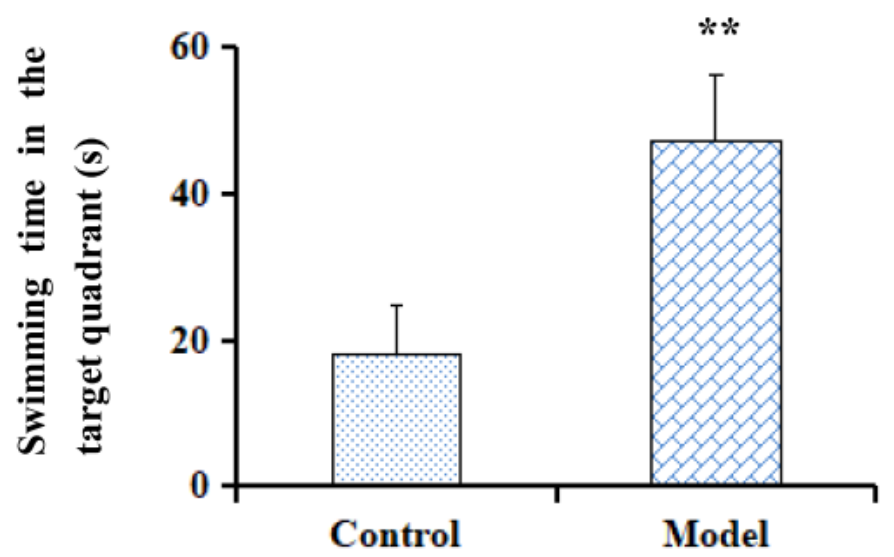

Figure 3. The swimming time in the target quadrant in trial sessions of the Morris water maze test. Data represent means \pm S.E.M. $\left(n=6,{ }^{* *} p<0.01\right.$ compared with the Control group).

\subsection{Method Validation}

\subsubsection{Selectivity}

With regard to typical multiple reaction monitoring (MRM) chromatograms of blank plasma, blank plasma spiked with two analytes at a lower limit of quantification (LLOQ, $0.1 \mathrm{ng} / \mathrm{mL}$ ) and the internal standard (IS). A normal group rat plasma sample $0.25 \mathrm{~h}$ after administration of extract of Alpinia oxyphylla fruits were shown in Figure 4. There was no endogenous interference being detected at retention times of chrysin (2.09 $\mathrm{min})$, tectochrysin $(3.30 \mathrm{~min})$, and paclitaxel (2.32 $\mathrm{min}$, IS), which proves satisfactory selectivity of the assay. 


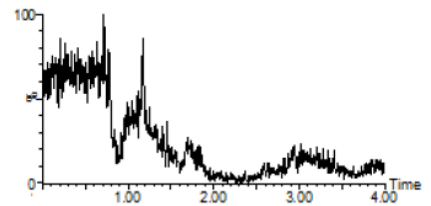

$255.0>153.1,9.63 \times 10^{4}$

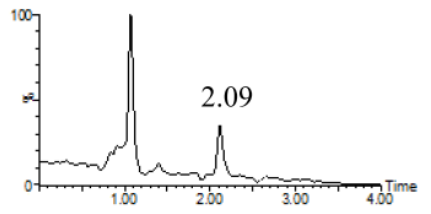

$255.0>153.1,1.07 \times 10^{5}$

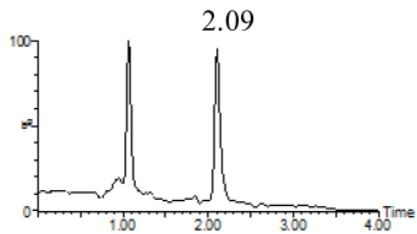

A

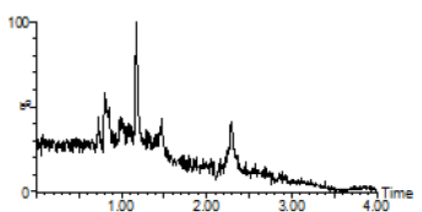

$269.0>225.7,3.76 \times 10^{5}$

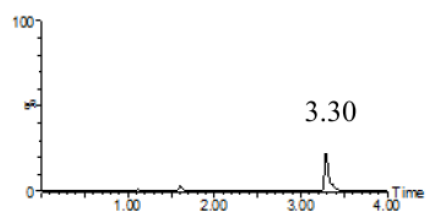

$269.0>225.7,2.31 \times 10^{5}$

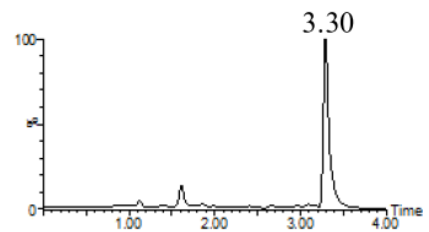

B

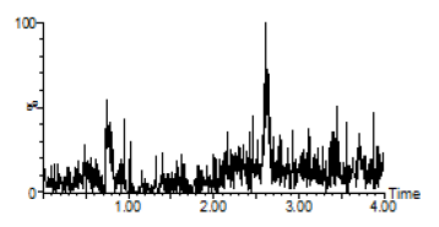

876.5 $>308.0,3.58 \times 10^{6}$

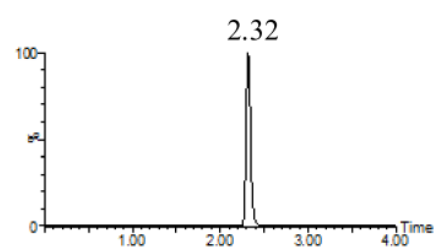

$876.5>308.0,3.30 \times 10^{6}$

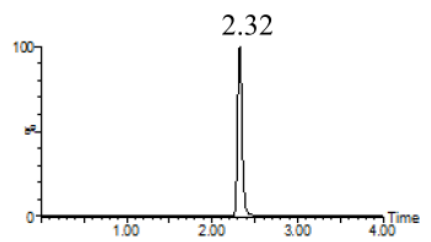

C

Figure 4. MRM chromatograms obtained from blank rat plasma, blank rat plasma spiked with analytes $(0.1 \mathrm{ng} / \mathrm{mL}, \mathrm{LLOQ})$ and the IS, and rat plasma $0.25 \mathrm{~h}$ after oral administration of Alpinia oxyphylla extract. Chromatograms of chrysin (A); tectochrysin (B); and IS (C).

\subsubsection{Calibration and LLOQ}

The calibration curves showed good linearity over the concentration range in rat plasma. A typical linear regression equation of the calibration curves were $y=0.05791 x-0.06715(r=0.9945), y=0.02034 x$ $+0.01833(r=0.9943)$ with the LLOQ of $0.1,0.1 \mathrm{ng} / \mathrm{mL}$ for chrysin and tectochrysin, respectively.

\subsubsection{Accuracy and Precision}

The accuracy of intra-day and inter-day precision data of the assays were shown in Table 1. The accuracies were all within $\pm 10.0 \%$. The intra-day and inter-day precisions for all analytes were less than $15 \%$, respectively. All the results of the tested samples were meeting the acceptable criterion (RSD $<15 \%$, RE within $\pm 15 \%$ ), which indicated that the developed method was accurate and reliable.

\subsubsection{Recovery and Matrix Effect}

The mean extraction recoveries of the two analytes were all more than $80.3 \%$ and the mean recovery of the IS was $82.7 \%$, which indicated that the recovery of analyte was precise and consistent. There was no significant matrix effect affecting the determination of the analytes and IS. The results were presented in Table 1. 
Table 1. Accuracy, precision, extraction recovery, and matrix effect for analysis of chrysin and tectochrysin in rat plasma $(n=6)$.

\begin{tabular}{|c|c|c|c|c|c|c|}
\hline & $\begin{array}{l}\text { Spiked Concentration } \\
\qquad(\mathrm{ng} / \mathrm{mL})\end{array}$ & Accuracy (RE\%) & Intra-Day RSD (\%) & Inter-Day RSD (\%) & $\begin{array}{c}\text { Recovery } \\
(\%, \text { Mean } \pm \text { SD })\end{array}$ & $\begin{array}{c}\text { Matrix Effect } \\
(\%, \text { Mean } \pm \text { SD })\end{array}$ \\
\hline \multirow{3}{*}{ Chrysin } & 0.2 & 6.9 & 9.8 & 9.3 & $80.3 \pm 3.7$ & $96.9 \pm 2.9$ \\
\hline & 2.0 & 7.5 & 5.6 & 6.2 & $84.6 \pm 5.5$ & $97.3 \pm 3.8$ \\
\hline & 40 & -8.8 & 4.9 & 5.0 & $86.7 \pm 2.8$ & $97.8 \pm 3.1$ \\
\hline \multirow[b]{2}{*}{ Tectochrysin } & 0.2 & 5.6 & 7.4 & 8.7 & $81.5 \pm 4.1$ & $98.2 \pm 4.5$ \\
\hline & 2.0 & 4.4 & 3.7 & 6.4 & $85.2 \pm 3.9$ & $97.7 \pm 4.2$ \\
\hline
\end{tabular}

\subsubsection{Stability}

Stability studies of the samples were run at three quality control (QC) levels. The results were shown in Table 2, which demonstrated that all the samples were stable at room temperature for $12 \mathrm{~h}$, at $-20{ }^{\circ} \mathrm{C}$ for 30 days after three freeze and thaw cycles, and at $4{ }^{\circ} \mathrm{C}$ in an auto-sampler for $12 \mathrm{~h}$ after being prepared.

Table 2. Stability of chrysin and tectochrysin in rat plasma $(n=3)$.

\begin{tabular}{ccccccc}
\hline \multirow{2}{*}{ Conditions } & \multicolumn{3}{c}{ Chrysin } & \multicolumn{3}{c}{ Tectochrysin } \\
\cline { 2 - 7 } & Spiked (ng/mL) & RE (\%) & RSD (\%) & Spiked (ng/mL) & RE (\%) & RSD (\%) \\
\hline \multirow{2}{*}{ Room temperature for 12 $\mathrm{h}$} & 0.2 & 4.9 & 7.8 & 0.2 & 5.8 & 7.2 \\
& 2.0 & -2.7 & 5.6 & 2.0 & 2.3 & 6.5 \\
& 40 & 1.6 & 4.1 & 40 & 3.1 & 5.6 \\
\hline \multirow{2}{*}{ Frozen for 30 d } & 0.2 & -2.6 & 8.6 & 0.2 & -4.9 & 8.4 \\
& 2.0 & 1.3 & 4.4 & 2.0 & -3.7 & 4.6 \\
& 40 & 3.8 & 6.2 & 40 & 2.5 & 5.1 \\
\hline \multirow{2}{*}{ Three freeze and thaw cycles } & 0.2 & -2.5 & 9.9 & 0.2 & -1.1 & 6.5 \\
& 2.0 & -5.6 & 4.6 & 2.0 & -2.9 & 5.7 \\
\hline \multirow{2}{*}{${ }^{\circ} \mathrm{C}$ in auto-sampler for 12 h } & 40 & 2.2 & 3.8 & 40 & -0.4 & 4.4 \\
in processed samples & 0.2 & 0.8 & 9.5 & 0.2 & 0.6 & 7.4 \\
& 2.0 & 4.4 & 4.7 & 2.0 & 3.6 & 6.8 \\
\hline
\end{tabular}

\subsection{Pharmacokinetic Study}

The utility of the UPLC-MS/MS method for the quantitation of two flavonoids in rat plasma was demonstrated after drug administration. The mean plasma concentration versus time profiles of chrysin and tectochrysin were illustrated in Figure 5. The main pharmacokinetic parameters were listed in Table 3.

Table 3. Main pharmacokinetic parameters of chrysin and tectochrysin after oral administration of Alpinia oxyphylla fruit extract (mean $\pm \mathrm{SD}, n=6$ ).

\begin{tabular}{ccccc}
\hline \multirow{2}{*}{ Parameters (Unit) } & \multicolumn{2}{c}{ Chrysin } & \multicolumn{2}{c}{ Tectochrysin } \\
\cline { 2 - 5 } & Normal Rat & Dementia Rat & Normal Rat & Dementia Rat \\
\hline $\mathrm{AUC}_{0-\mathrm{t}}(\mathrm{ng} \mathrm{h} / \mathrm{mL})$ & $78.81 \pm 25.21$ & $131.1 \pm 44.6^{* *}$ & $10.99 \pm 3.45$ & $20.40 \pm 4.54^{* *}$ \\
$\mathrm{AUC}_{0-\infty}(\mathrm{ng}$ & $81.6 \pm 29.34$ & $135.1 \pm 47.4^{* *}$ & $13.25 \pm 3.98$ & $23.59 \pm 4.68^{* *}$ \\
$\mathrm{~h} / \mathrm{mL})$ & $18.06 \pm 4.31$ & $29.28 \pm 8.72^{*}$ & $9.87 \pm 3.01$ & $19.29 \pm 5.05^{* *}$ \\
$C_{\max }(\mathrm{ng} / \mathrm{mL})$ & $4.51 \pm 1.02$ & $4.22 \pm 0.89$ & $3.72 \pm 0.82$ & $3.14 \pm 0.71$ \\
$t_{1 / 2}(\mathrm{~h})$ & $0.25,8$ & $0.25,8$ & 0.25 & 0.25 \\
$T_{\max }(\mathrm{h})$ & $7.52 \pm 1.34$ & $7.45 \pm 1.19$ & $4.12 \pm 1.16$ & $3.54 \pm 1.11$ \\
$\mathrm{MRT}(\mathrm{h})$ & $6.127 \pm 1.514$ & $3.702 \pm 0.775^{* *}$ & $75.49 \pm 30.85$ & $42.39 \pm 26.76^{* *}$ \\
$\mathrm{CL}_{\text {F }}(\mathrm{L} \cdot \mathrm{kg} / \mathrm{h})$ & &
\end{tabular}

${ }^{*} p<0.05,{ }^{* *} p<0.01$ compared with the normal rats. 
A

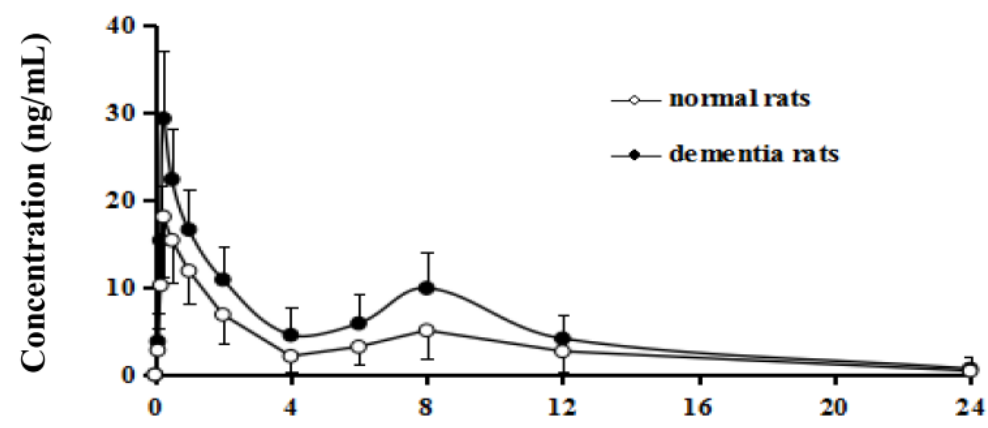

Time (h)

B

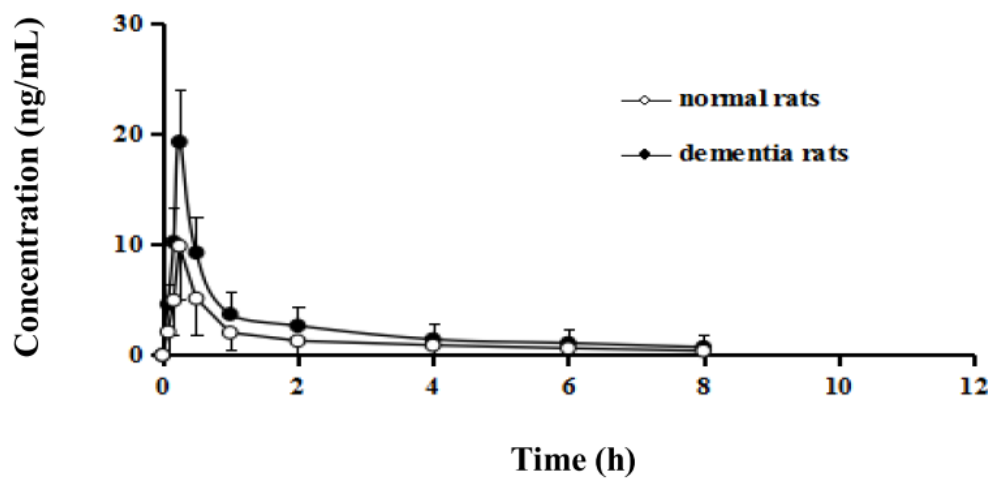

Figure 5. The mean plasma concentration versus time profiles of chrysin (A) and tectochrysin (B) in rat plasma after oral administration of Alpinia oxyphylla fruit extract $(n=6)$.

As shown in Table 3, two flavonoids showed low AUC and $C_{\max }$ in plasma due to their relative low levels in the crude drug and partly forming mono-glucuronide metabolites in plasma [19]. Chrysin exhibited rapid absorption and a bimodal phenomenon in plasma concentration-time profiles, which was consistent with the previous studies [21,22]. The first peak occurred at about $0.25 \mathrm{~h}$ and the second at $8 \mathrm{~h}$ due to the glucuronidation [19] and enterohepatic circulation [23]. Moreover, there were statistically remarkable differences on the pharmacokinetic parameters of AUC, $C_{\max }$, and CL_F of the two analytes between normal and dementia rats. Compared with the normal rats, the $C_{\max }, \mathrm{AUC}_{0-\mathrm{t}}$, and $\mathrm{AUC}_{0-\infty}$ in dementia rats were remarkably increased $(p<0.01)$.The CL_F was decreased significantly $(p<0.01)$ after oral administration of extract of $A$. oxyphylla dried fruits, which indicated a better absorption and slower elimination of the test constituents in an $A \beta$-induced AD model of dementia rats.

The reason for better uptake of the constituents in $\mathrm{AD}$ rats may include the following. $\mathrm{AD}$ is a progressive and complex neurodegenerative disorder characterized by extracellular deposited amyloid- $\beta$ peptide and intracellular hyper-phosphorylated and tangled tau-protein [24]. AD pathogenesis also involves vascular abnormalities such as alterations to the neurovascular unit [25] and decreases in cerebral blood flow [26]. Fibrinogen is a plasma glycoprotein that circulates at a high concentration in the blood and is essential for coagulation since it is converted into fibrin in response to injury [27]. Evidence has indicated a key role for fibrinogen and fibrin clot formation in AD pathogenesis [28,29]. Fibrinogen could increase the viscosity of blood [30] and cause poor blood circulation, which might cause a longer residence time of the drugs in the blood.

The other reason is that, in AD patients, the levels of blood hydroxyl radicals increase regularly [31]. Glutathione, which is a major antioxidant, plays a crucial role in the protection of tissues from radical injury [32]. The cost of glutathione needs more precursor glutamine, which is vital for the production of ATP and the main respiratory material of the small intestine [33]. Flavonoids have 
been reported to be modulators of P-glycoprotein (Pgp), which could bind strongly to a Pgp cytosolic site [34]. The two constituents are probably to be pumped out by Pgp [35] and the decreased glutamine would cause a decline of ATP levels and a reduction in the function of P-glycoprotein, which is combined with the longer residence time of the drugs in a small intestine. Further pharmacokinetic study of the two constituents after intravenous (i.v.) administration should be carried out to elucidate the hypothesis mentioned above. Essentially, the results indicated that the two flavonoids showed a better absorption rate under pathological conditions in rats.

\section{Materials and Methods}

\subsection{Materials and Reagents}

Alpinia oxyphylla fruits were obtained from the Shenyang Tongrentang Drug Company (Shenyang, China) and the source of the herbs is the Hainan province. Chrysin, tectochrysin (purity $>99.8 \%$ ), and paclitaxel (purity $>99.5 \%$, IS) were purchased from the National Institutes for Food and Drug Control (Beijing, China).The A $\beta_{1-42}$ peptide was provided by Sigma-Aldrich (St. Louis, MO, USA). HPLC-grade methanol was obtained from Fisher Scientific (Fair Lawn, NJ, USA). Ethanol, diethyl ether of analytical grade were purchased from Shandong Yuwang Industrial (Yucheng, China). Distilled water was provided by Wahaha Co. Ltd. (Hangzhou, China).

\subsection{The Extract Preparation of Alpinia oxyphylla}

The air-dried fruits of A. oxyphylla were extracted with 95\% ethanol under reflux 3 times for $2 \mathrm{~h}$ each time. After being concentrated under vacuum, the extract was suspended in $0.5 \%$ CMC-Na for administration to the rats.

\subsection{Animals and Treatment}

Male SPF grade Sprague-Dawley (SD) rats $(230 \pm 20 \mathrm{~g})$ were obtained from the Experimental Animal Center of Shenyang Pharmaceutical University. The animal study was performed according to the Guideline for Animal Experimentation of Shenyang Pharmaceutical University and the protocol was approved by the Animal Ethics Committee of the institution (SCXK 2015-001).

Twelve SD rats were divided into two groups randomly and given different treatments. The rats in the model group were anesthetized with chloralhydrate $(200 \mathrm{mg} / \mathrm{kg}$ body weight, i.p.) and injected with aggregated $10 \mu \mathrm{L}$ of the $\mathrm{A} \beta_{1-42}$ peptide $\left(\mathrm{A} \beta_{1-42}\right.$ peptide was dissolved in physiological saline to a concentration of $1.0 \mu \mathrm{g} / \mu \mathrm{L}$ and incubated at $37^{\circ} \mathrm{C}$ for $5 \mathrm{~d}$ to get the aggregated form) into the left lateral ventricle ( $\mathrm{AP},-3.0 \mathrm{~mm}, \mathrm{ML}, \pm 2.2 \mathrm{~mm}, \mathrm{DV},-3.0 \mathrm{~mm}$ ) [36].

\subsection{The Morris Water Maze Test}

To demonstrate the success of the model after $A \beta$ injection, a water maze test was carried out by the Morris method with minor modification [37]. Parameters included escape latency time in order to find a platform, search strategy, and swimming time in the target quadrant, which were recoded for evaluating the spatial learning ability and memory of the tested object.

\subsection{Instruments and UPLC-MS/MS Conditions}

The assay was performed on an Acquity ${ }^{\mathrm{TM}}$ ultra-performance liquid chromatography system coupled with the Xevo TQ-S mass spectrometer (Waters, Milford, MA, USA). MassLynx software V4.1 was used for data acquisition and processing. The separation was conducted using an Acquity UPLC BEH C $\mathrm{C}_{18}$ column $(2.1 \mathrm{~mm} \times 100 \mathrm{~mm}, 1.7 \mu \mathrm{m}$, Waters, Milford, MA, USA) packed with a BEH $C_{18}$ pre-column $(2.1 \mathrm{~mm} \times 5 \mathrm{~mm}, 1.7 \mu \mathrm{m})$ with column temperature setting at $35^{\circ} \mathrm{C}$. Gradient elution was employed with a mobile phase composed of $0.1 \%$ formic acid-water (A) and methanol (B) with the following parameters: 0-2 $\mathrm{min}, 65-75 \% \mathrm{~B}, 2.01-3.5 \mathrm{~min}, 75-90 \% \mathrm{~B}, 3.51-5.0 \mathrm{~min}, 65 \% \mathrm{~B}$. The mass spectrometer was operated in multiple reaction monitoring modes (MRM) using electrospray 
in the positive ionization mode with two precursor ion/product ion transitions for each analyte. The precursor-to-product ion pairs for chrysin, tectochrysin, and paclitaxel were $m / z 255.0 \rightarrow 153.1$, $269.0 \rightarrow 225.7$, and $876.5 \rightarrow 308.0$, respectively (Figure 6). Other optimal parameters include a curtain voltage of $3.0 \mathrm{kV}$, a source temperature of $150{ }^{\circ} \mathrm{C}$, and a desolvation temperature of $350{ }^{\circ} \mathrm{C}$.

A
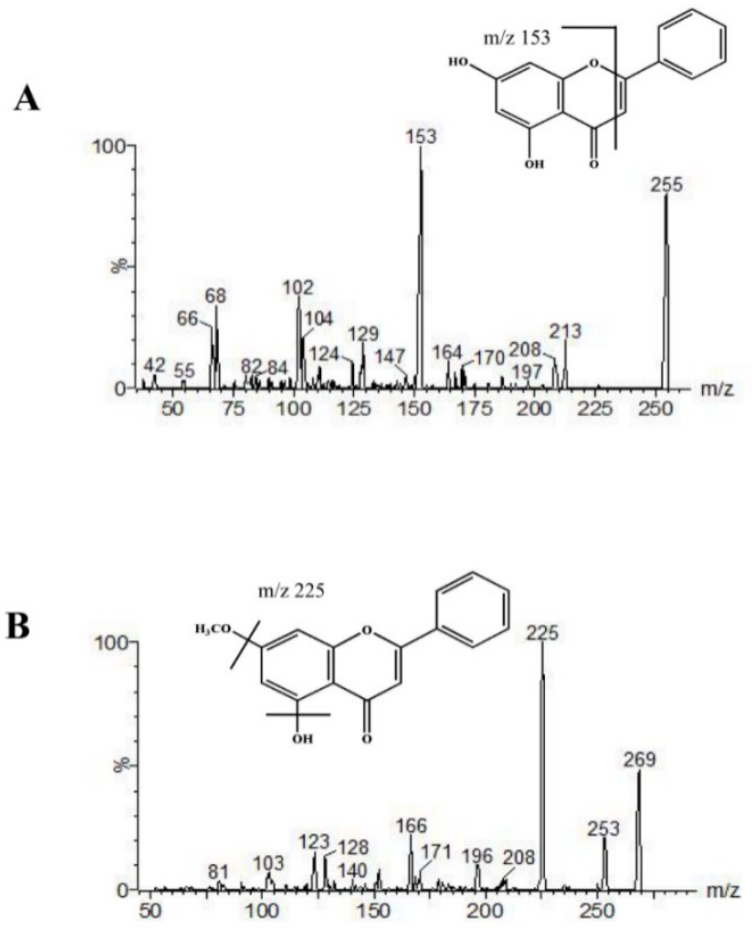

Figure 6. Product ion mass spectra of $[\mathrm{M}+\mathrm{H}]^{+}$ions of chrysin $(\mathbf{A})$ and tectochrysin $(\mathbf{B})$ in positive mode.

\subsection{Standard Solution and Quality Control Samples}

Standard stock solutions of chrysin, tectochrysin, and IS were prepared in methanol at concentrations of $1.0 \mathrm{mg} / \mathrm{mL}$. Calibration standard solutions for chrysin and tectochrysin were prepared by diluting mixed stock solutions with methanol. IS solution was obtained by diluting to a concentration of $500 \mathrm{ng} / \mathrm{mL}$ with methanol as well.

Calibration standards of chrysin and tectochrysin $(0.1 \mathrm{ng} / \mathrm{mL}, 0.25 \mathrm{ng} / \mathrm{mL}, 1.0 \mathrm{ng} / \mathrm{mL}, 5.0 \mathrm{ng} / \mathrm{mL}$, $10 \mathrm{ng} / \mathrm{mL}, 25 \mathrm{ng} / \mathrm{mL}$, and $50 \mathrm{ng} / \mathrm{mL}$ ) were obtained by spiking a series of the working standard solution to drug-free rat plasma. Quality control (QC) samples at three levels $(0.2 \mathrm{ng} / \mathrm{mL}, 2.0 \mathrm{ng} / \mathrm{mL}$, and $40 \mathrm{ng} / \mathrm{mL}$ ) were prepared separately in the same way.

\subsection{Sample Preparation}

Plasma samples of $100 \mu \mathrm{L}$ were spiked with $10 \mu \mathrm{L}$ methanol and $10 \mu \mathrm{L}$ IS (500 ng/mL) and extracted with diethyl ether $(1 \mathrm{~mL})$ by vortex shaking for $5 \mathrm{~min}$. The samples were centrifuged at $4000 \mathrm{rpm}$ for $5 \mathrm{~min}$ and then the organic layer was transferred to another tube and evaporated to dryness at $35{ }^{\circ} \mathrm{C}$ under a slight stream of nitrogen. Then the residue was reconstituted with a $100 \mu \mathrm{L}$ initial mobile phase and vortexing for $1 \mathrm{~min}$. Finally, $5 \mu \mathrm{L}$ of the solution was injected for UPLC-MS/MS analysis.

\subsection{Method Validation}

The method was validated in accordance with US FDA guidelines [38]. Selectivity was tested by comparing chromatograms of blank rat plasma with plasma samples spiked with two analytes and the IS at LLOQ. The linearity was measured by analyzing the calibration curves using least-squares 
linear regression analysis of the analytes-to-IS peak area ratios versus the nominal concentration of the calibration standard with a weighed factor $\left(1 / x^{2}\right)$. LLOQ was defined as the lowest concentration on the calibration curve with an acceptable accuracy within $\pm 20 \%$ and precision less than $20 \%$. QC samples at low, medium, and high levels were analyzed on three separate occasions with six replicates at each concentration per occasion to determine accuracy and precision. The extraction recovery of the two analytes were assessed at three QC concentrations with six replicates by comparing the peak areas from extracted samples with those from post-extracted blank plasma samples spiked with the analytes. The matrix effect was determined by comparing the peak response of blank plasma extracts spiked with the analytes to the peak response of a pure standard solution containing equivalent amounts of the compounds at three QC levels. Stability studies in plasma samples were assessed at three QC levels under four different storage conditions, which include room temperature for $12 \mathrm{~h}$, frozen at $-20{ }^{\circ} \mathrm{C}$ for $30 \mathrm{~d}$, three freeze-thaw cycles, and samples after being prepared at $4{ }^{\circ} \mathrm{C}$ for $12 \mathrm{~h}$. The acceptable criteria of accuracy, extraction recovery, matrix effect, and stability were all within $\pm 15 \%$ and the precision was less than $15 \%$.

\subsection{Pharmacokinetic Application}

The method was applied toward determining chrysin and tectochrysin levels in rat plasma after oral administration of ethanol extract of Alpinia oxyphylla fruits (at a dose containing chrysin $0.25 \mathrm{mg} / \mathrm{kg}$, tectochrysin $1.0 \mathrm{mg} / \mathrm{kg}$ ). Blood samples (about $0.3 \mathrm{~mL}$ ) were obtained from the suborbital vein into heparinized tubes before administration and $0.08 \mathrm{~h}, 0.17 \mathrm{~h}, 0.25 \mathrm{~h}, 0.5 \mathrm{~h}, 1 \mathrm{~h}, 2 \mathrm{~h}, 4 \mathrm{~h}, 6 \mathrm{~h}, 8 \mathrm{~h}, 12$ $\mathrm{h}$, and $24 \mathrm{~h}$ after dosing. It was then centrifuged at 15,000 rpm for $5 \mathrm{~min}$ immediately. Plasma samples were stored at $-20^{\circ} \mathrm{C}$.

The plasma concentrations of two analytes at different points were presented as mean \pm SD. The mean concentration-time curves were plotted and all the pharmacokinetic parameters were calculated using DAS 2.1 software package (Chinese Pharmacological Society, Beijing, China). Comparisons of pharmacokinetic data between normal and dementia groups were processed by using SPSS software 19.0 where $p<0.05$ was considered statistically significant for all the tests.

\section{Conclusions}

A simple and sensitive UPLC-MS/MS method has been established and validated for determining chrysin and tectochrysin in rat plasma. The method has been successfully applied to a comparative pharmacokinetic study between normal rats and dementia rats after oral administration of the ethanol extract of Alpinia oxyphylla dried fruits. The results indicated that the absorption of the two compounds was significantly increased in dementia rats than that in normal rats. The established method and the pharmacokinetic results could provide useful information for preclinical studies of active constituents in A. oxyphylla, which has potential therapeutic effects on neurodegenerative diseases.

Author Contributions: X.Z. conceived and designed the experiments. X.Z. and C.L. performed the experiments. X.S. analyzed the data. X.Z. wrote the paper. Y.J. reviewed the paper. All authors read and approved the final manuscript.

Funding: This research was funded by the National Natural Science Foundation of China (No. 81403065) and the China Postdoctoral Science Foundation (No. 2017M621163).

Acknowledgments: This research was supported by the National Natural Science Foundation of China (No. 81403065) and the China Postdoctoral Science Foundation (No. 2017M621163).

Conflicts of Interest: The authors declare no conflict of interest.

\section{References}

1. Kubo, M.; Matsuda, H.; Suo, T.; Yamanaka, J.; Sakanaka, M.; Yoshimura, M. Study on Alpiniae Fructus. I. Pharmacological evidence of efficacy of Alpiniae Fructus on ancient herbal literature. Yakugaku Zasshi 1995, 115, 852-862. [CrossRef] [PubMed] 
2. Shi, S.H.; Zhao, X.; Liu, A.J.; Liu, B.; Li, H.; Wu, B.; Bi, K.S.; Jia, Y. Protective effect of n-butanol extract from Alpinia oxyphylla on learning and memory impairments. Physiol. Behav. 2015, 139, 13-20. [CrossRef] [PubMed]

3. Shi, S.H.; Zhao, X.; Liu, B.; Li, H.; Liu, A.J.; Wu, B.; Bi, K.S.; Jia, Y. The effects of sesquiterpenes-rich extract of Alpinia oxyphylla Miq. on amyloid- $\beta$-induced cognitive Impairment and neuronal abnormalities in the cortex and hippocampus of mice. Oxid. Med. Cell. Longev. 2014, 2014, 451802. [CrossRef] [PubMed]

4. Liu, A.J.; Zhao, X.; Li, H.; Liu, Z.; Liu, B.; Mao, X.; Guo, L.; Bi, K.S.; Jia, Y. 5-Hydroxymethylfurfural, an antioxidant agent from Alpinia oxyphylla Miq. improves cognitive impairment in $A \beta_{1-42}$ mouse model of Alzheimer's disease. Int. Immunopharmacol. 2014, 23, 719-725. [CrossRef] [PubMed]

5. Yan, T.X.; Wu, B.; Liao, Z.Z.; Liu, B.; Zhao, X.; Bi, K.S.; Jia, Y. Brain-derived neurotrophic factor signaling mediates the antidepressant-like effect of the total flavonoids of Alpiniae oxyphyllae Fructus in chronic unpredictable mild stress mice. Phytother. Res. 2016, 30, 1493-1502. [CrossRef] [PubMed]

6. Zhang, J.Q.; Wang, S.; Li, Y.H.; Xu, P.; Chen, F.; Tan, Y.F.; Duan, J.A. Anti-diarrheal constituents of Alpinia oxyphylla. Fitoterapia 2013, 89, 149-156. [CrossRef] [PubMed]

7. He, Z.H.; Ge, W.; Yue, G.G.; Lau, C.B.; He, M.F.; But, P.P. Anti-angiogenic effects of the fruit of Alpinia oxyphylla. J. Ethnopharmacol. 2010, 132, 443-449. [CrossRef] [PubMed]

8. Zhang, X.; Shi, G.F.; Liu, X.Z.; An, L.J.; Guan, S. Anti-ageing effects of protocatechuic acid from Alpinia on spleen and liver antioxidative system of senescent mice. Cell Biochem. Funct. 2011, 29, 342-347. [CrossRef] [PubMed]

9. Yu, X.Y.; An, L.J.; Wang, Y.Q.; Zhao, H.; Gao, C.Z. Neuroprotective effect of Alpinia oxyphylla Miq. fruits against glutamate-induced apoptosis in cortical neurons. Toxicol. Lett. 2003, 144, 205-212. [CrossRef]

10. Wong, K.K.; Wan, C.C.; Shaw, P.C. P4-427 Ethanol extract of Alpinia oxyphylla fructus shows inhibition of tau protein phosphorylation in cell culture. Neurobiol. Aging 2004, 25, 595-597. [CrossRef]

11. Price, D.L.; Sisodia, S.S. Cellular and molecular biology of Alzheimer's disease and animal models. Annu. Rev. Med. 1994, 45, 435-446. [CrossRef] [PubMed]

12. Citron, M.; Oltersdorf, T.; Haass, C.; McConlogue, L.; Hung, A.Y.; Seubert, P.; Vigo-Pelfrey, C.; Lieberburg, I.; Selkoe, D.J. Mutation of the $\beta$-amyloid precursor protein in familial Alzheimer's disease increases $\beta$-protein production. Nature 1992, 360, 672-674. [CrossRef] [PubMed]

13. Hardy, J.; Selkoe, D.J. The amyloid hypothesis of Alzheime's disease: Progress and problems on the road to therapeutics. Science 2002, 297, 353-356. [CrossRef] [PubMed]

14. Zhao, X.; Liao, Z.Z.; Qi, Y.; Shen, X.; Bi, K.S.; Jia, Y. Antioxidative activity of methyl amygdalinate from the seeds of Prunus persica and neuroprotective effects on $\mathrm{A} \beta_{1-42}$-induced neurodegeneration models. RSC Adv. 2016, 6, 93794-93800. [CrossRef]

15. Luo, X.Z.; Yu, J.G.; Xu, L.Z.; Yang, S.L.; Feng, J.D.; Ou, S.L. Chemical constituents in volatile oil from fruits of Alpinia oxyphylla Miq. China J. Chin. Mater. Med. 2001, 26, 262-264.

16. Liu, H.; Guo, S.Y.; Xiao, K.J.; Cai, M.Y.; Han, C.R. Extraction of Alpinia oxyphylla Miquel essence via supercritical carbon dioxide and antioxidant activity of the extracts. J. South China Univ. Technol. 2006, 34, $54-57$.

17. Nabavi, S.F.; Braidy, N.; Habtemariam, S.; Orhan, I.E.; Daglia, M.; Manayi, A.; Gortzi, O.; Nabavi, S.M. Neuroprotective effects of chrysin: From chemistry to medicine. Neurochem. Int. 2015, 90, 224-231. [CrossRef] [PubMed]

18. Mantawy, E.M.; El-Bakly, W.M.; Esmat, A.; Badr, A.M.; El-Demerdash, E. Chrysin alleviates acute doxorubicin cardiotoxicity in rats via suppression of oxidative stress, inflammation and apoptosis. Eur. J. Pharmacol. 2014, 728, 107-118. [CrossRef] [PubMed]

19. Chen, F.; Li, H.L.; Tan, Y.F.; Li, Y.H.; Lai, W.Y.; Guan, W.W.; Zhang, J.Q.; Zhao, Y.S.; Qin, Z.M. Identification of known chemicals and their metabolites from Alpinia oxyphylla fruit extract in rat plasma using liquid chromatography/tandem mass spectrometry (LC-MS/MS) with selected reaction monitoring. J. Pharm. Biomed. 2014, 97, 166-177. [CrossRef] [PubMed]

20. Wen, Q.; Li, H.L.; Tan, Y.F.; Zhang, X.G.; Qin, Z.M.; Li, W.; Li, Y.H.; Zhang, J.Q.; Chen, F. LC-MS/MS-based method for simultaneous quantification of known chemicals and metabolites of Alpiniae oxyphyllae Fructus extract in rat plasma and its application in a pharmacokinetic study. Anal. Methods 2016, 8, 2069-2081. [CrossRef] 
21. Tong, L.; Wan, M.X.; Zhang, L.H.; Zhu, Y.H.; Sun, H.; Bi, K.S. Simultaneous determination of baicalin, wogonoside, baicalein, wogonin, oroxylin A and chrysin of Radix scutellariae extract in rat plasma by liquid chromatography tandem mass spectrometry. J. Pharm. Biomed. 2012, 70, 6-12. [CrossRef] [PubMed]

22. Zhu, Y.H.; Tong, L.; Zhou, S.P.; Sun, H.; Bi, K.S.; Zhang, B.L. Simultaneous determination of active flavonoids and alkaloids of Tang-Min-Ling-Pill in rat plasma by liquid chromatography tandem mass spectrometry. J. Chromatogr. B 2012, 904, 51-58. [CrossRef] [PubMed]

23. Akao, T.; Kawabata, K.; Yananisawa, E.; Ishihara, K.; Mizuhara, Y.; Wakui, Y.; Sakashita, Y.; Kobashi, K. Balicalin, the predominant flavone glucuronide of scutellariae radix, is absorbed from the rat gastrointestinal tract as the aglycone and restored to its original form. J. Pharm. Pharmacol. 2000, 52, 1563-1568. [CrossRef] [PubMed]

24. Selkoe, D.J. Alzheimer's Disease: Genotypes, Phenotype, and Treatments. Science 1997, $275,630-631$. [CrossRef] [PubMed]

25. Iadecola, $\mathrm{C}$. The overlap between neurodegenerative and vascular factors in the pathogenesis of dementia. Acta Neuropathol. 2010, 120, 287-296. [CrossRef] [PubMed]

26. Mazza, M.; Marano, G.; Traversi, G.; Bria, P.; Mazza, S. Primary cerebral blood flow deficiency and Alzheimer's disease: Shadows and lights. J. Alzheimers Dis. 2011, 23, 375-389. [CrossRef] [PubMed]

27. Weisel, J.W. Fibrinogen and fibrin. Adv. Protein Chem. 2005, 70, 247-299. [PubMed]

28. Cortes-Canteli, M.; Paul, J.; Norris, E.H.; Bronstein, R.; Ahn, H.J.; Zamolodchikov, D.; Bhuvanendran, S.; Fenz, K.M.; Strickland, S. Fibrinogen and beta-amyloid association alters thrombosis and fibrinolysis: A possible contributing factor to Alzheimer's disease. Neuron 2010, 66, 695-709. [CrossRef] [PubMed]

29. Paul, J.; Strickland, S.; Melchor, J.P. Fibrin deposition accelerates neurovascular damage and neuroinflammation in mouse models of Alzheimer's disease. J. Exp. Med. 2007, 204, 1999-2008. [CrossRef] [PubMed]

30. Chien, S.; Usami, S.; Dellenback, R.J.; Gregersen, M.I.; Nanninga, L.B.; Guest, M.M. Blood viscosity: Influence of erythrocyte aggregation. Science 1967, 157, 829-831. [CrossRef] [PubMed]

31. Ihara, Y.; Hayabara, T.; Sasaki, K.; Fujisawa, Y.; Kawada, R.; Yamamoto, T.; Nakashima, Y.; Yoshimune, S.; Kawai, M.; Kibata, M.; et al. Free radicals and superoxide dismutase in blood of patients with Alzheimer's disease and vascular dementiam. J. Neurol. Sci. 1997, 153, 76-81. [CrossRef]

32. Harlan, J.M.; Levine, J.D.; Callahan, K.S.; Schwartz, B.R.; Harker, L.A. Glutathione redox cycle protects cultured endothelial cells against lysis by extracellularly generated hydrogen peroxide. J. Clin. Investig. 1984, 73, 706-713. [CrossRef] [PubMed]

33. Windmueller, H.G.; Spaeth, A.E. Identification of ketone bodies and glutamineas the major respiratory fuels in vivo for post absorptive rat small intestine. J. Biol. Chem. 1978, 253, 69-76. [PubMed]

34. Conseil, G.; Baubichon-Cortay, H.; Dayan, G.; Jault, J.M.; Barron, D.; Di Pietro, A. Flavonoids: A class of modulators with bifunctional interactions at ATP- and Steroid-binding sites of the mouse P-glycoprotein. Proc. Natl. Acad. Sci. USA 1998, 95, 9831-9836. [CrossRef] [PubMed]

35. Comte, G.; Daskiewicz, J.B.; Bayet, C.; Conseil, G.; Viorneryvanier, A.; Dumontet, C.; Di Pietro, A.; Barron, D. C-Isoprenylation of flavonoids enhances binding affinity toward P-glycoprotein and modulation of cancer cell chemoresistance. J. Med. Chem. 2001, 44, 763-768. [CrossRef] [PubMed]

36. George, P.; Charles, W. The Rat Brain in Stereotaxic Coordinates: Hard Cover Edition; Academic Press: London, UK, 2007.

37. Morris, R. Development of a water-maze procedure for studying spatial learning in the rat. J. Neurosci. Meth. 2007, 11, 47-60. [CrossRef]

38. Food and Drug Administration. Guidance for Industry: Bioanalytical Method Validation. Available online: https:/ / www.fda.gov/downloads/Drugs/Guidance/ucm070107.pdf (accessed on 18 June 2004).

Sample Availability: Samples of the extract of Alpinia oxyphylla fruits are available from the authors. 